\title{
Nanosecond laser ablation and deposition of silicon
}

\author{
Wee Ong Siew • Seong Shan Yap • Cécile Ladam · \\ Øystein Dahl · Turid Worren Reenaas · Teck Yong Tou
}

Received: 9 August 2010 / Accepted: 8 April 2011 / Published online: 7 May 2011

(C) The Author(s) 2011. This article is published with open access at Springerlink.com

\begin{abstract}
Nanosecond-pulsed $\mathrm{KrF}(248 \mathrm{~nm}, 25 \mathrm{~ns})$ and Nd:YAG $(1064 \mathrm{~nm}, 532 \mathrm{~nm}, 355 \mathrm{~nm}, 5 \mathrm{~ns})$ lasers were used to ablate a polycrystalline $\mathrm{Si}$ target in a background pressure of $<10^{-4} \mathrm{~Pa}$. Si films were deposited on $\mathrm{Si}$ and GaAs substrates at room temperature. The surface morphology of the films was characterized using scanning electron microscopy (SEM) and atomic force microscopy (AFM). Round droplets from $20 \mathrm{~nm}$ to $5 \mu \mathrm{m}$ were detected on the deposited films. Raman Spectroscopy indicated that the micron-sized droplets were crystalline and the films were amorphous. The dependence of the properties of the films on laser wavelengths and fluence is discussed.
\end{abstract}

\section{Introduction}

Nasnosecond-pulsed-laser deposition (PLD) has not been extensively used for semiconducting films fabrication such as $\mathrm{Si}$ because of particulates incorporation in the films [1-4]. Si based generation of nanomaterials, however, has been explored when materials condensed in the form of nanocrystals, nanoparticles or nanoclusters by PLD [5-16]. Fundamental laser parameters which include pulse length,

W.O. Siew $\cdot$ T.Y. Tou

Faculty of Engineering, Multimedia University, 63100 Cyberjaya,

Selangor, Malaysia

S.S. Yap $(\bowtie) \cdot$ T.W. Reenaas

Department of Physics, Norwegian University of Science

and Technology, 7491 Trondheim, Norway

e-mail: seong.yap@ntnu.no

Fax: +47-73597710

C. Ladam $• \varnothing$. Dahl

SINTEF Materials and Chemistry, 7465 Trondheim, Norway wavelength and fluence determine the ablation/the onset of plasma formation, thus govern the production of large particulates as well as nano-sized clusters. Si nanoclusters with radii between $5-25 \mathrm{~nm}$ have been deposited at $0.5 \mathrm{~J} / \mathrm{cm}^{2}$ in high vacuum using a femtosecond (fs) laser [16], while particles with a size from $2 \mathrm{~nm}$ to $>20 \mathrm{~nm}$ were deposited using a picosecond (ps) laser in vacuum [13]. For a nanosecond (ns) laser, even smaller particles have been obtained: 2-5 nm, but only in the presence of a background medium such as liquid [5] and background gases [9, 15, 17-19]. The density of the medium affects the momentum transfer; cooling rate, spatial and energy distribution of plasma plume. On the other hand, the laser wavelength has also been proposed to affect the size of nanocrystallite, causing a shift in the peak photoluminescence energy $[18,20]$. The correlations of these fundamental parameters for deposition of Si films or synthesis of nanoparticles, although important for both fundamental understanding and technology applications, are still far from completely understood.

In this work, we performed ns pulsed-laser deposition of $\mathrm{Si}$ in vacuum, with the aim to address the effects of laser wavelength and fluence on the film morphology, and formation of micron and nano-sized Si droplets.

\section{Experimental}

A $\mathrm{KrF}$ excimer laser (248 nm, $25 \mathrm{~ns})$ and a Nd-YAG laser $(1064 \mathrm{~nm}, 532 \mathrm{~nm}, 355 \mathrm{~nm}, 5 \mathrm{~ns})$ were used for the ablation and deposition (10 Hz repetition rate, 18000 pulses) from a polycrystalline Si (sputtering) target (Kurt J. Lesker, undoped, $99.999 \% \mathrm{Si}$ ). The laser beam of $248 \mathrm{~nm}$ was imaged by using a slit and focusing lens to obtain a homogeneous beam on the target, and beam size was $0.009 \mathrm{~cm}^{2}$. For $355 \mathrm{~nm}, 532 \mathrm{~nm}$ and $1064 \mathrm{~nm}$, the laser beams were 


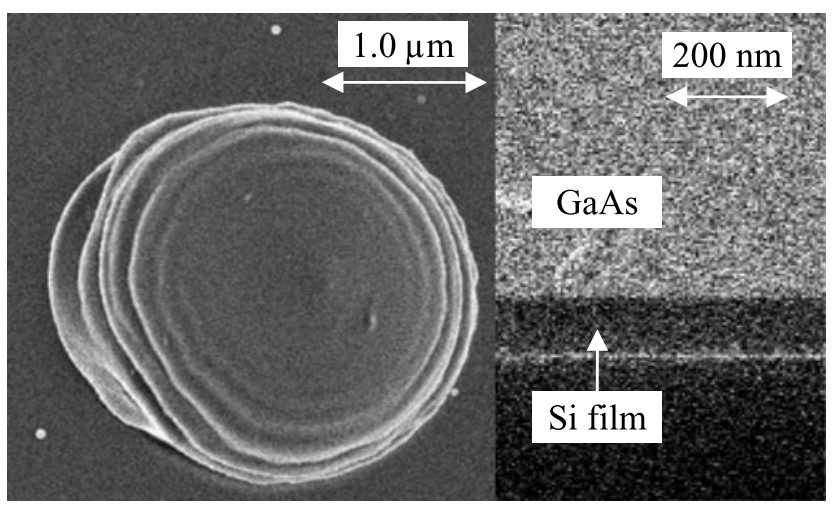

Fig. 1 A micron-sized droplets and small nano-droplets of Si film on GaAs and inset shows the cross section of the film

focus to a spot size of $0.003 \mathrm{~cm}^{2}$. The laser beam was incident at an angle of $45^{\circ}$ and the laser fluence was varied in the range of $1.5-6 \mathrm{~J} / \mathrm{cm}^{2}$. Si (100) and GaAs (100) substrates were placed $45 \mathrm{~mm}$ from the target. Depositions were performed at room temperature with a background pressure of $<10^{-4} \mathrm{~Pa}$. The thickness of the films was obtained by using ellipsometry and a shadow mask method. The step created using the mask was measured using a white light interferometric microscope (Zygo) and a profilometer (Veeco Dektak Profiler). The films' morphology was characterized using scanning electron microscopy (SEM, Zeiss Ultra, Hitachi S5500), atomic force microscopy (AFM, Digital Instrument) and Raman spectroscopy (Horiba HR800UV, $633 \mathrm{~nm}$, incident power $=8.5 \mathrm{~mW}$ ).

\section{Results and discussion}

Micron and nano-sized droplets were found on the films deposited at high fluence and long laser wavelengths. Figure 1 shows the SEM image of a sample deposited by using $532 \mathrm{~nm}$ laser where a large droplet was surrounded by smaller droplets of diameter $<100 \mathrm{~nm}$. The inset shows the cross section of the film of about $120 \mathrm{~nm}$. The film has a broad peak in the Raman spectrum centered at around $485 \mathrm{~cm}^{-1}$, indicating that it is amorphous. A sharp peak at $522 \mathrm{~cm}^{-1}$ on a broad background was obtained by positioning the Raman probe beam onto a large micron-sized droplet; indicating that the droplet is crystalline (Fig. 2). This has also been observed by others [2,3].

Table 1 shows the properties of $\mathrm{Si}$ films deposited on $\mathrm{Si}$ substrates at $3 \mathrm{~J} / \mathrm{cm}^{2}$ for different laser wavelengths. The $\mathrm{Si}$ film deposited at $248 \mathrm{~nm}$ was relatively thin as compared to films deposited at other laser wavelengths despite the larger beam size which should have resulted in smaller angular distribution of the ablated materials. The effective power density $\left(3.8 \times 10^{7} \mathrm{~W} / \mathrm{cm}^{2}\right)$ was one order of magnitude lower than other wavelengths $\left(3.2-4.1 \times 10^{8} \mathrm{~W} / \mathrm{cm}^{2}\right)$ because of

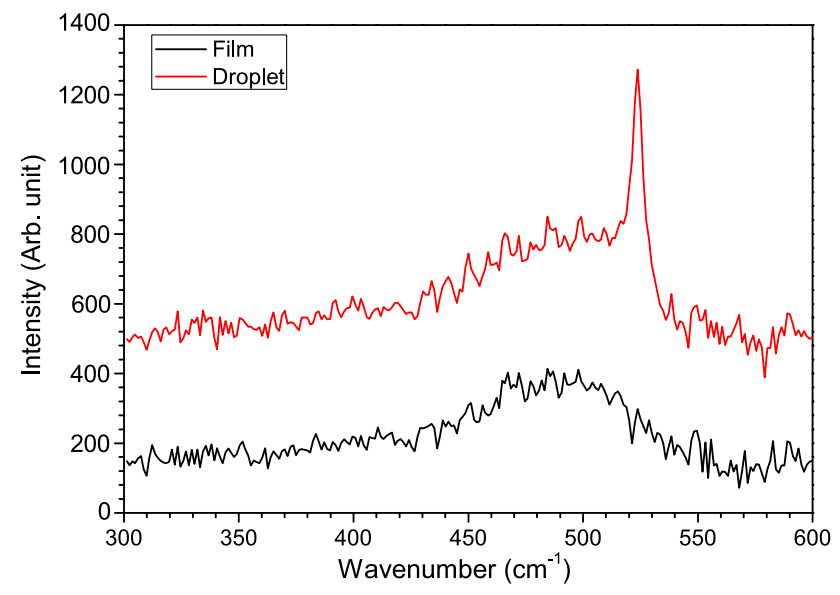

Fig. 2 Raman spectra on a micron-sized droplet as compared to a spectrum obtained at an area without large droplets

higher reflection and longer pulse duration at $248 \mathrm{~nm}$. Thus, the power density could be below the threshold for high density plasma formation. For deposition using NdYAG laser, it was observed that the growth rate was lowest when longer wavelength laser was used. The average roughness $R_{\mathrm{a}}$, obtained on a droplet-free area, was in the range of $0.11 \mathrm{~nm}$ on silicon substrate and 0.12 on the GaAs, slightly higher than the bare substrates. The morphology of the films is shown in Fig. 3.

While the large micron-sized droplets were crystalline (Fig. 1), the nano-sized droplets were most likely amorphous, unlike the nanocrystallites deposited by using a picoseconds $355 \mathrm{~nm}$ laser at room temperature, vacuum and similar fluence [8]. In the report, nanocrystallites with an average size of $1.5 \mathrm{~nm}$ gave a Raman peak at $500 \mathrm{~cm}^{-1}$ with full width half maximum of $\sim 30 \mathrm{~cm}^{-1}$, which was absent in our films. The mean diameter of our nano-sized droplets obtained here varied from 30 to $60 \mathrm{~nm}$ and the height increased with laser wavelength, but remained $<6 \mathrm{~nm}$. Figure 4 shows the cross section analysis of typical nano-sized droplets that were found on the Si films. The density of the droplets with diameters $<0.5 \mu \mathrm{m}$ were determined from an area of $5 \times 5 \mu^{2}$ by using AFM, and the densities of the larger droplets were obtained from SEM images with $500 \times$ magnification from an area of $15.4 \times 22.8 \mu^{2}$. The size distribution of the droplets for samples deposited at $3 \mathrm{~J} / \mathrm{cm}^{2}$ on $\mathrm{Si}$ at different wavelength is shown in Fig. 5. Overall, the densities of micron and nano-sized droplets increased when the laser wavelength increased. Most droplets were $<0.5 \mu \mathrm{m}$ and large droplet of $>1 \mu \mathrm{m}$ was not detected for the film deposited using $248 \mathrm{~nm}$. The effect of laser fluence at $1064 \mathrm{~nm}$ is shown in Fig. 6. The density of droplets $<0.5 \mu \mathrm{m}$ using $1064 \mathrm{~nm}$ decreased with increasing laser fluence as compared to other laser wavelengths, due to the fact that removal of the materials at high laser fluence for $1064 \mathrm{~nm}$ was dominated by ejection of large micron size droplets. 
Table 1 Si films deposited on Si at different laser wavelengths at $\sim 3 \mathrm{~J} / \mathrm{cm}^{2}$

\begin{tabular}{|c|c|c|c|c|c|c|c|c|}
\hline \multirow{2}{*}{$\begin{array}{l}\lambda \\
(\mathrm{nm})\end{array}$} & \multirow{2}{*}{$\begin{array}{l}\text { Thickness } \\
(\mathrm{nm})\end{array}$} & \multicolumn{2}{|c|}{$\begin{array}{l}\text { Roughness } \\
(\mathrm{nm})\end{array}$} & \multicolumn{3}{|c|}{ Droplets $<0.5 \mu \mathrm{m}$} & \multirow{2}{*}{$\begin{array}{l}\text { Droplets } \\
0.5-1.0 \mu \mathrm{m} \\
\begin{array}{l}\text { Density } \\
\left(\mathrm{cm}^{2}\right)\end{array}\end{array}$} & \multirow{2}{*}{$\begin{array}{l}\text { Droplets } \\
>1.0 \mu \mathrm{m} \\
\begin{array}{l}\text { Density } \\
\left(\mathrm{cm}^{2}\right)\end{array}\end{array}$} \\
\hline & & $R_{\mathrm{rms}}$ & $R_{\mathrm{a}}$ & $\begin{array}{l}\text { Density } \\
\left(\mathrm{cm}^{2}\right)\end{array}$ & $\begin{array}{l}\text { Mean diameter } \\
(\mathrm{nm})\end{array}$ & $\begin{array}{l}\text { Mean height } \\
(\mathrm{nm})\end{array}$ & & \\
\hline 248 & 3 & 0.130 & 0.103 & $2.4 \times 10^{7}$ & 30.0 & 1.1 & $4.3 \times 10^{4}$ & 0 \\
\hline 355 & 82 & 0.136 & 0.108 & $1.7 \times 10^{8}$ & 34.5 & 2.0 & $1.2 \times 10^{5}$ & $1.1 \times 10^{4}$ \\
\hline 532 & 57 & 0.137 & 0.109 & $2.9 \times 10^{8}$ & 65.5 & 4.8 & $1.3 \times 10^{5}$ & $1.1 \times 10^{4}$ \\
\hline 1064 & 35 & 0.154 & 0.114 & $4.3 \times 10^{8}$ & 50.4 & 4.3 & $1.3 \times 10^{5}$ & $2.2 \times 10^{4}$ \\
\hline
\end{tabular}

Fig. 3 AFM images of a typical droplets-free area of the amorphous $\mathrm{Si}$ films on (a) $\mathrm{Si}$ and (b) GaAs, as compared to an uncoated (c) Si and (d) GaAs

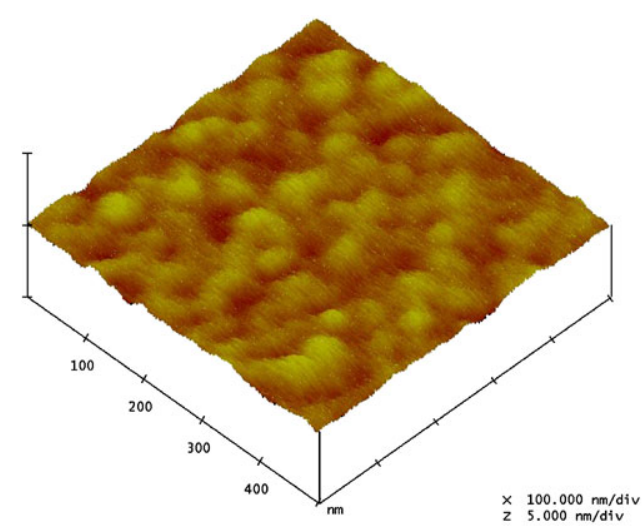

a

a sisiirbosumf.006

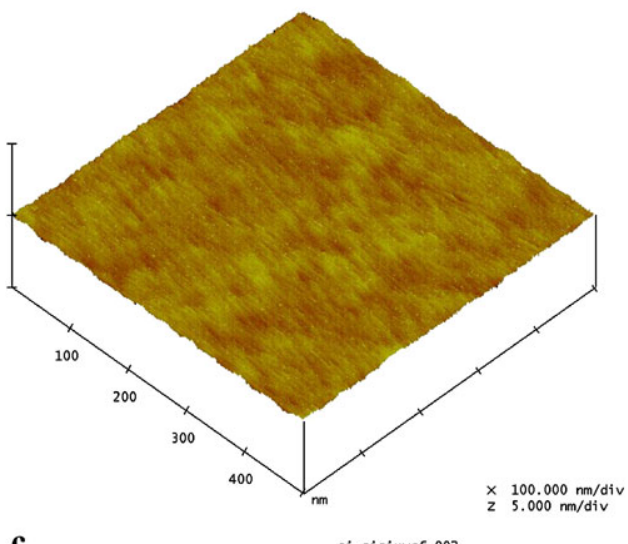

c

si-sisiuvcf. 002

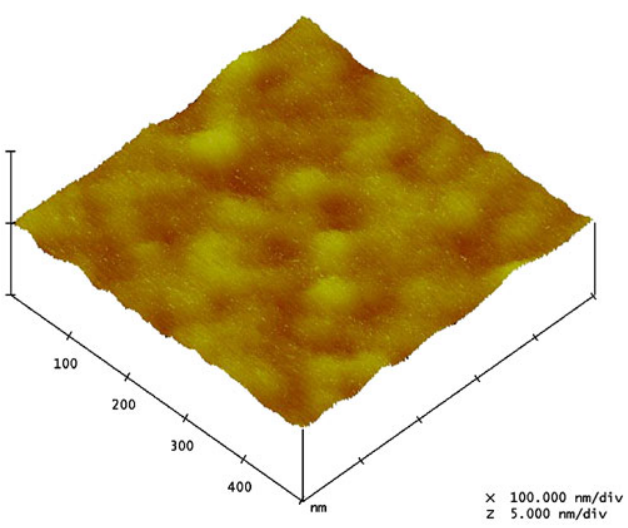

b sigairbf. 012

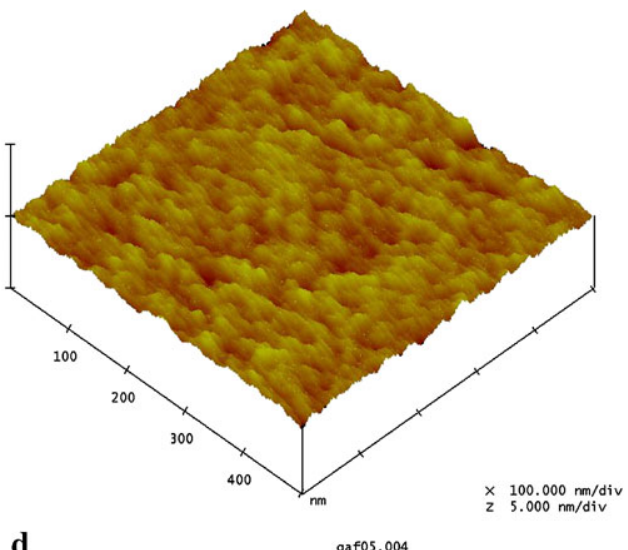

The origin of large micron-sized droplets is often related to the liquid phase expulsion and explosive boiling at elevated fluence [21, 22]. Figure 7 shows the target surface after film deposition at $6 \mathrm{~J} / \mathrm{cm}^{2}$. The ablated area on the target for $1064 \mathrm{~nm}$ was distinctly different from the others, several crack lines were present. Recent theoretical and experimental studies of wavelength dependence studies in phase explosion of $\mathrm{Si}$ gave a threshold irradiance of $10^{10}$ and $10^{11} \mathrm{~W} / \mathrm{cm}^{2}$ for $266 \mathrm{~nm}$ and $523 \mathrm{~nm}$ laser [23]. As our energy was still far below these threshold and the droplets were mostly $<3 \mu \mathrm{m}$ at wavelength shorter that $1064 \mathrm{~nm}$, the large droplets in our case maybe due to hydrodynamic instability or roughening of the target surface upon multiple irradiations. For $1064 \mathrm{~nm}$ ablation, a crude estimate gave a laser penetration depth of $10^{-3} \mathrm{~cm}$, such that the laser en- ergy will be deposited into a larger volume as compared to the other wavelengths. Subsequently, material removal might include a large number of melt crystalline droplets and less ionized species. Since lower fraction of ejected materials in the plasma plume was then responsible for the growth of amorphous film, the resultant films were thinner than those grown at other laser wavelengths. Shockwave and recoil pressure for such a deposition condition are unlikely so thermal stresses by repeated heating and cooling may instead be responsible for the crack line.

In all the films, the size of the droplets was rarely below $30 \mathrm{~nm}$ diameter although the mean height could be down to 1-2 nm. The diameters, although larger than those obtained in ps laser deposition in vacuum, increase in size with laser fluence for all laser wavelengths, as in the case of using 


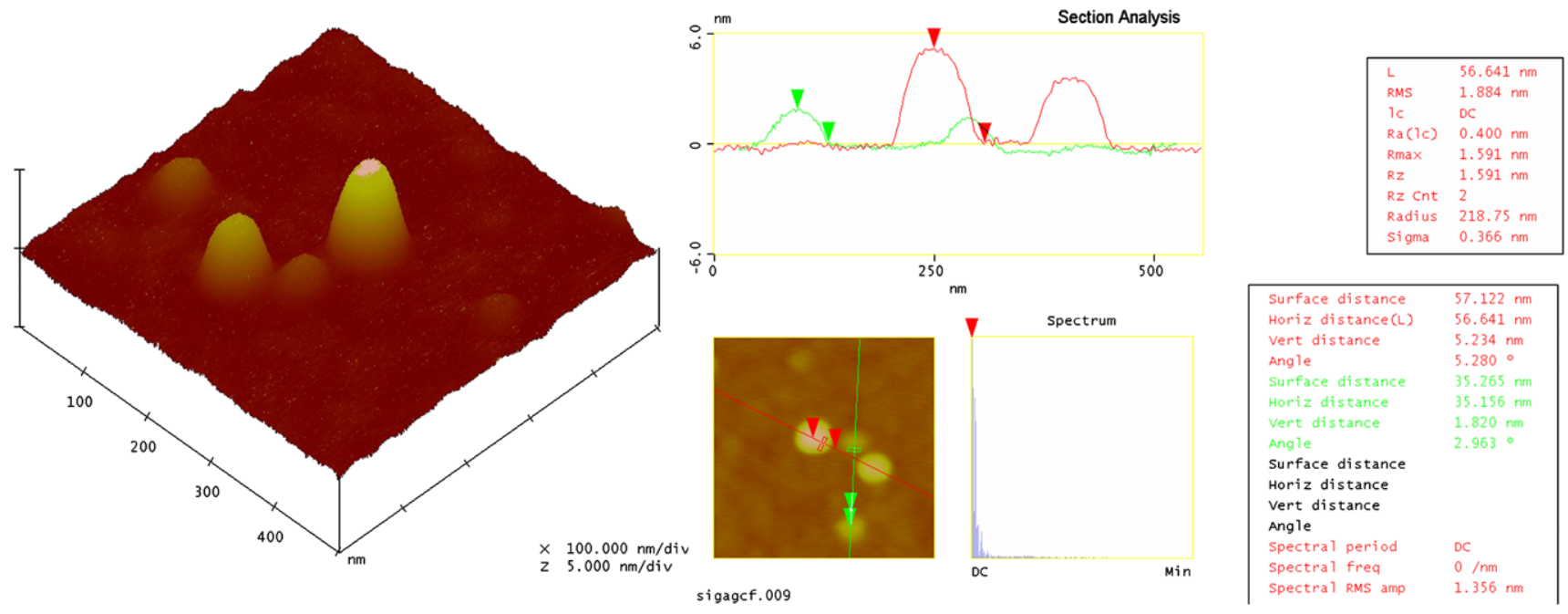

Fig. 4 AFM of nano-sized droplets where the height was 1.82 to $5.5 \mathrm{~nm}$

Fig. 5 The density of droplets of different size deposited by $248 \mathrm{~nm}, 355 \mathrm{~nm}, 532 \mathrm{~nm}$ and $1064 \mathrm{~nm}$ at $3 \mathrm{~J} / \mathrm{cm}^{2}$

Fig. 6 Density of droplets at $1.5 \mathrm{~J} / \mathrm{cm}^{2}, 3 \mathrm{~J} / \mathrm{cm}^{2}$ and $6 \mathrm{~J} / \mathrm{cm}^{2}$ for films deposited by $1064 \mathrm{~nm}$, where mean diameter for droplets $<0.5 \mu \mathrm{m}$ were $41 \mathrm{~nm}$, $50 \mathrm{~nm}$ and $71 \mathrm{~nm}$, respectively
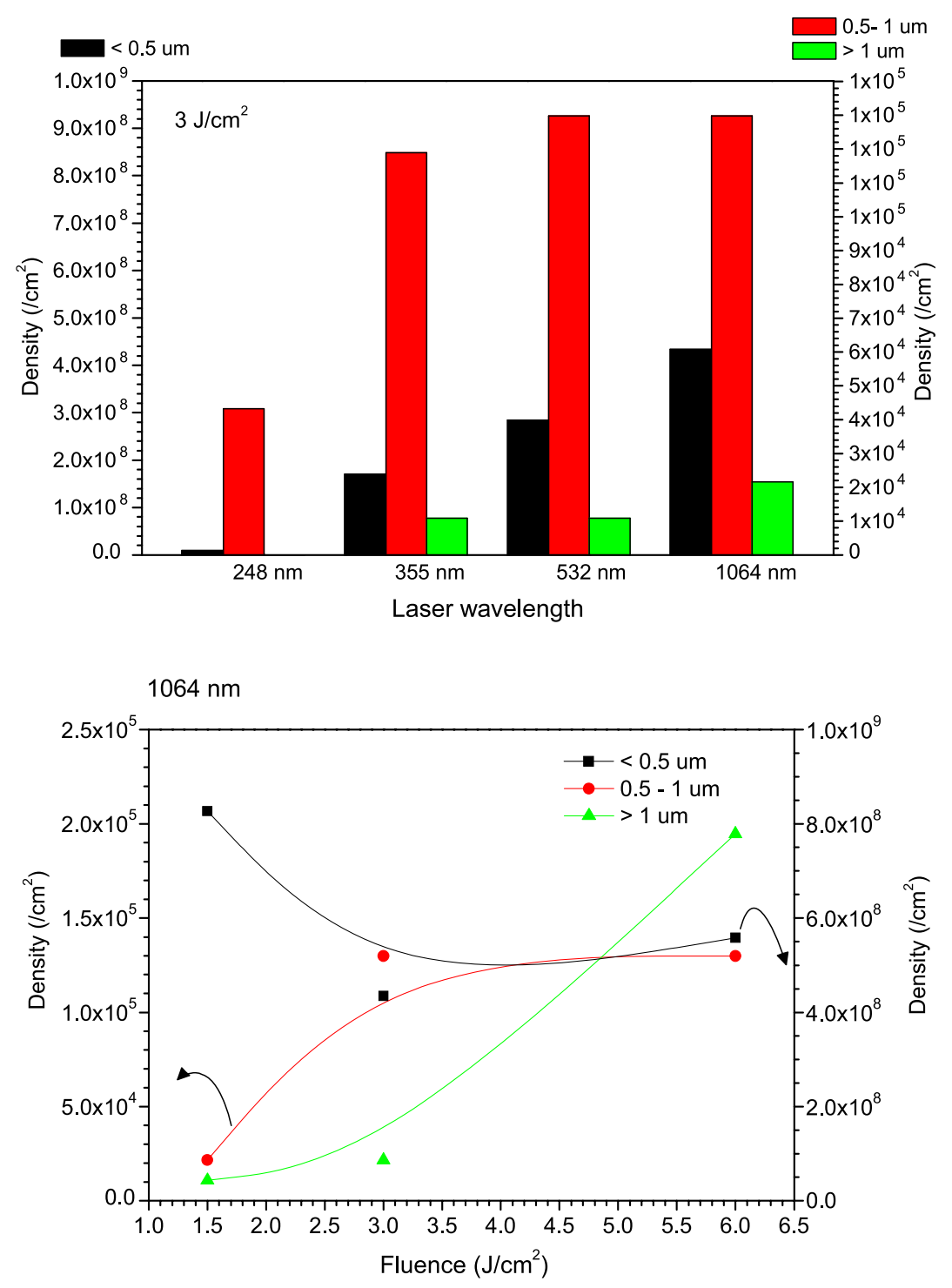


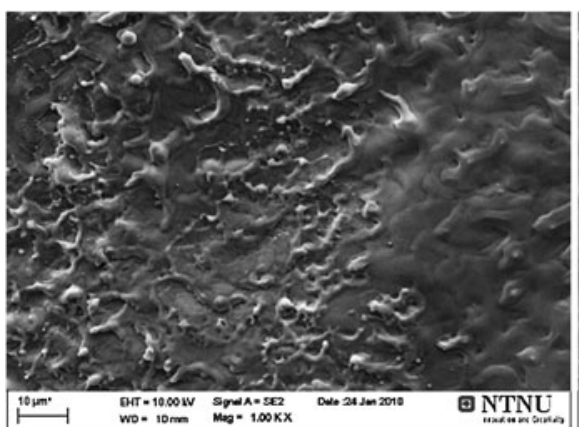

a

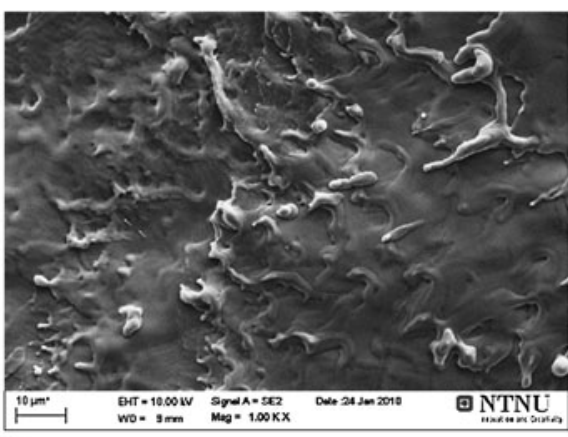

b

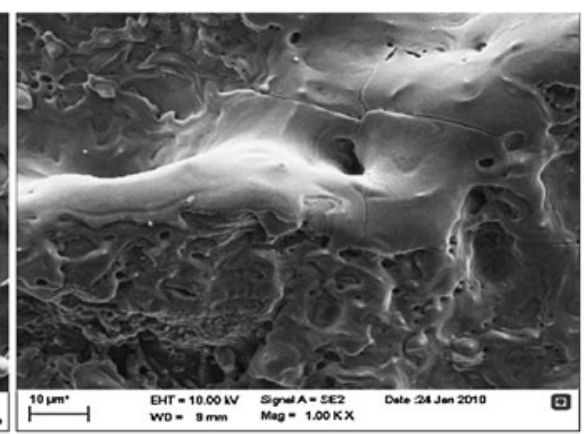

c

Fig. 7 SEM images of the target surface after ablation at $6 \mathrm{~J} / \mathrm{cm}^{2}$ for: (a) $355 \mathrm{~nm}$, (b) $532 \mathrm{~nm}$ and (c) $1064 \mathrm{~nm}$

a ps laser [13]. The formation of these nano-sized droplets is believed to be different from those grown in various background gases with a size of $1-10 \mathrm{~nm}$; here the formation was related to plasma plume confinement from the background/buffer gas that enhanced collision and promoted aggregate formation [24]. In addition, the process should be different from fs laser ablation of Si in vacuum, where the formation is related to the sudden expansion upon laser irradiation instead of condensation in gas phase [16]. The other possibility is that the nano-sized droplets were partly produced by disintegrating of the large droplets via laser plasma interaction, which was less likely for ps and fs and short laser wavelength deposition.

\section{Summary}

We have presented results of Si deposition at different laser wavelengths and fluences by PLD. Amorphous Si films and droplets of $20 \mathrm{~nm}$ to $5 \mu \mathrm{m}$ were deposited at $248 \mathrm{~nm}$, $355 \mathrm{~nm}, 532 \mathrm{~nm}$ and $1064 \mathrm{~nm}$ laser wavelengths. Amorphous Si films were grown from the ionized species of the laser-ablated plasma plume, while large micron-sized crystalline Si droplets were most likely originated from the process of liquid phase expulsion; mainly for high fluence, long laser wavelength deposition. Smaller droplets of $20 \mathrm{~nm}$ to $500 \mathrm{~nm}$ coexisted in the films deposited at all laser wavelengths and fluences in this work.

Acknowledgements We acknowledge the Research Council of Norway (project number 181886) and Malaysian Ministry of Higher Education (FRGS/1/10/SG/MMU/01/01(ST)).

Open Access This article is distributed under the terms of the Creative Commons Attribution Noncommercial License which permits any noncommercial use, distribution, and reproduction in any medium, provided the original author(s) and source are credited.

\section{References}

1. Z. Andreic, V. Henc-Bartolic, D. Gracin, M. Stubicar, Appl. Surf. Sci. 136, 73 (1998)

2. S. Viayalakshmi, Z. Iqbal, M.A. George, J. Federici, H. Grebel, Thin Solid Films 339, 102 (1999)

3. S. Yasuda, T. Chikyow, S. Inoue, N. Matsuki, K. Miyazaki, S. Nishio, M. Kakihana, H. Koinuma, Appl. Phys. A 69, S925 (1999)

4. L. Cultrera, M.I. Zeifman, A. Perrone, Phys. Rev. B 73 (2006)

5. V. Svrcek, D. Mariotti, M. Kondo, Opt. Express 17, 520 (2009)

6. S.H. Bae, S.Y. Lee, H.Y. Kim, S. Im, Opt. Mater. 17, 87 (2001)

7. J.H. Kim, K.A. Jeon, G.H. Kim, S.Y. Lee, Opt. Mater. 27, 991 (2005)

8. B. Polyakov, A. Petruhins, J. Butikova, A. Kuzmin, I. Tale, Eur. Phys. J. Appl. Phys. 48, 20502 (2009)

9. K. Murakami, T. Makimura, N. Ono, T. Sakuramoto, A. Miyashita, O. Yoda, Appl. Surf. Sci. 127, 368 (1998)

10. S. Vijayalakshmi, M.A. George, J. Sturmann, H. Grebel, Appl. Surf. Sci. 127, 378 (1998)

11. W. Marine, L. Patrone, B. Luk'yanchuk, M. Sentis, Appl. Surf. Sci. 154, 345 (2000)

12. L. Patrone, D. Nelson, V.I. Safarov, S. Giorgio, M. Sentis, W. Marine, Appl. Phys. A 69, S217 (1999)

13. M.H. Wu, R. Mu, A. Ueda, D.O. Henderson, B. Vlahovic, Mater. Sci. Eng. B, Solid-State Mater. Adv. Technol. 116, 273 (2005)

14. Y.L. Wang, Z.C. Deng, G.S. Fu, Y. Zhou, L.Z. Chu, Y.C. Peng, Thin Solid Films 515, 1897 (2006)

15. Y.L. Wang, L.Z. Chu, Y.L. Li, G.S. Fu, Micro Nano Lett. 4, 39 (2009)

16. S. Amoruso, R. Bruzzese, N. Spinelli, R. Velotta, M. Vitiello, X. Wang, G. Ausanio, V. Iannotti, L. Lanotte, Appl. Phys. Lett. 84, $4502(2004)$

17. T. Makino, N. Suzuki, Y. Yamada, T. Yoshida, T. Seto, N. Aya, Appl. Phys. A 69, S243 (1999)

18. J.H. Kim, K.A. Jeon, J.B. Choi, S.Y. Lee, Mater. Sci. Eng. B, Solid-State Mater. Adv. Technol. 101, 146 (2003)

19. P.M. Ossi, M. Dinescu, in Laser Processing of Materials: Fundamentals, Applications and Developments, ed. by P. Schaaf (Springer, Berlin, 2010), p. 131

20. J.H. Kim, K.A. Jeon, E.S. Shim, S.Y. Lee, Mater. Sci. Eng. B, Solid-State Mater. Adv. Technol. 89, 70 (2002)

21. J.H. Yoo, S.H. Jeong, R. Greif, R.E. Russo, J. Appl. Phys. 88, 1638 (2000)

22. V. Craciun, N. Bassim, R.K. Singh, D. Craciun, J. Hermann, C. Boulmer-Leborgne, Appl. Surf. Sci. 186, 288 (2002)

23. Q. Lu, S.S. Mao, X. Mao, R.E. Russo, J. Appl. Phys. 104, 083301 (2008)

24. A. Bailini, P.M. Ossi, Europhys. Lett. 79, 35002 (2007) 